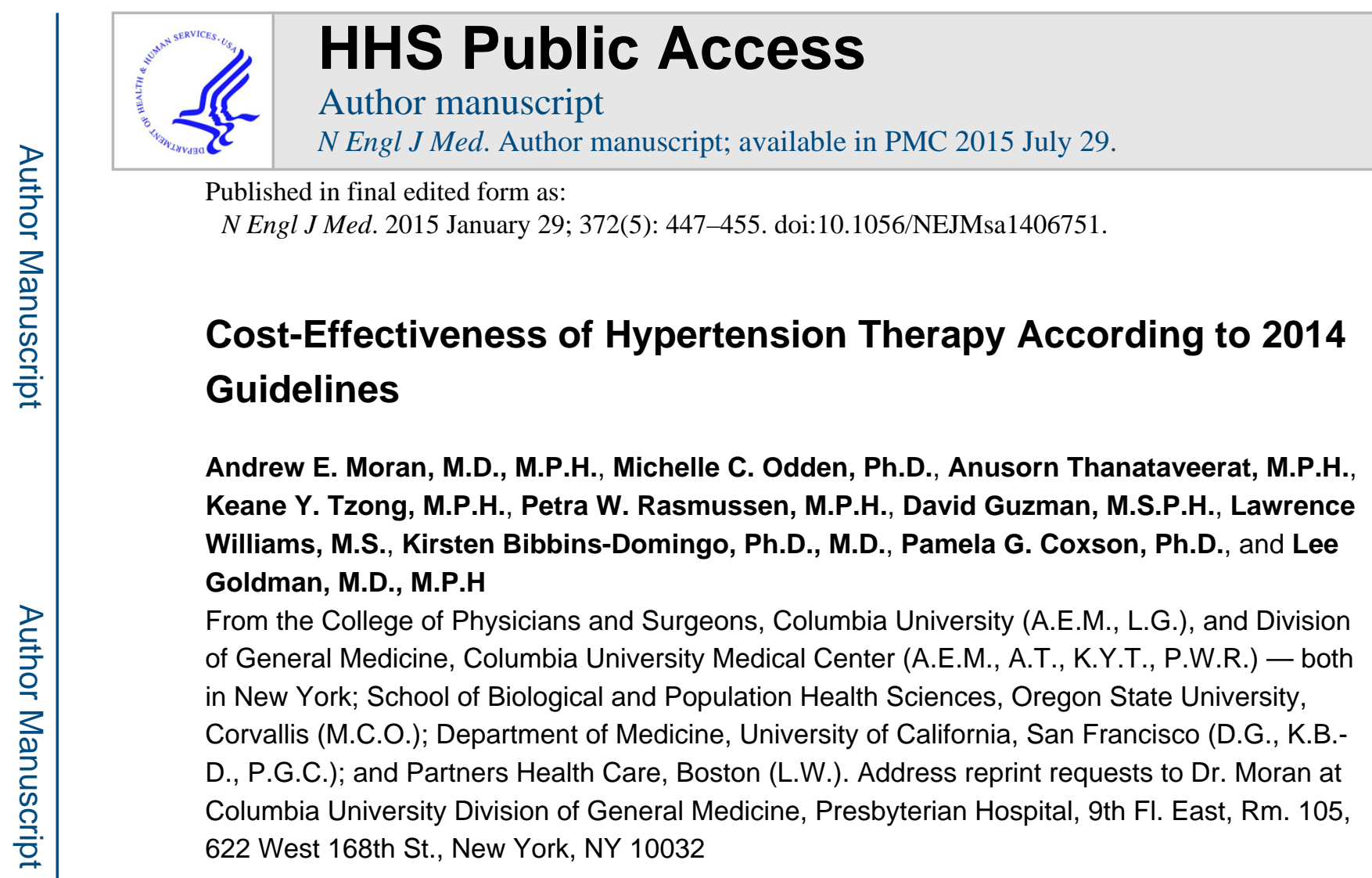

\title{
Abstract
}

BACKGROUND—On the basis of the 2014 guidelines for hypertension therapy in the United States, many eligible adults remain untreated. We projected the cost-effectiveness of treating hypertension in U.S. adults according to the 2014 guidelines.

\begin{abstract}
METHODS-We used the Cardiovascular Disease Policy Model to simulate drug-treatment and monitoring costs, costs averted for the treatment of cardiovascular disease, and quality-adjusted life-years (QALYs) gained by treating previously untreated adults between the ages of 35 and 74 years from 2014 through 2024. We assessed cost-effectiveness according to age, hypertension level, and the presence or absence of chronic kidney disease or diabetes.
\end{abstract}

RESULTS-The full implementation of the new hypertension guidelines would result in approximately 56,000 fewer cardiovascular events and 13,000 fewer deaths from cardiovascular causes annually, which would result in overall cost savings. The projections showed that the treatment of patients with existing cardiovascular disease or stage 2 hypertension would save lives and costs for men between the ages of 35 and 74 years and for women between the ages of 45 and 74 years. The treatment of men or women with existing cardiovascular disease or men with stage 2 hypertension but without cardiovascular disease would remain cost-saving even if strategies to increase medication adherence doubled treatment costs. The treatment of stage 1 hypertension was cost-effective (defined as $<\$ 50,000$ per QALY) for all men and for women between the ages of 45

Copyright () 2015 Massachusetts Medical Society aem35@cumc.columbia.edu..

Dr. Bibbins-Domingo is a member and vice chair of the U.S. Preventive Services Task Force (USPSTF). The views expressed in this article are those of the authors and do not necessarily represent the views and policies of the USPSTF.

Disclosure forms provided by the authors are available with the full text of this article at NEJM.org. 
and 74 years, whereas treating women between the ages of 35 and 44 years with stage 1 hypertension but without cardiovascular disease had intermediate or low cost-effectiveness.

CONCLUSIONS-The implementation of the 2014 hypertension guidelines for U.S. adults between the ages of 35 and 74 years could potentially prevent about 56,000 cardiovascular events and 13,000 deaths annually, while saving costs. Controlling hypertension in all patients with cardiovascular disease or stage 2 hypertension could be effective and cost-saving. (Funded by the National Heart, Lung, and Blood Institute and others.)

In the United States, more deaths from cardiovascular causes are attributed to elevated blood pressure than to any other risk factor. ${ }^{1,2}$ Since 1960 , there has been a decline of approximately $10 \%$ in the mean systolic blood pressure and a decline of approximately $13 \%$ in the mean diastolic blood pressure among adults over the age of 40 years, in part because of greater awareness of the risk and more widespread treatment of hypertension. ${ }^{3}$

Nonetheless, the number of persons with hypertension is increasing, and an estimated $44 \%$ of the 64 million U.S. adults with hypertension did not have this condition controlled in 2014. Thus, there is an enormous potential for improving population health by expanding treatment and improving control. ${ }^{4}$

A decade ago, the 2003 hypertension guidelines of the Seventh Joint National Committee focused on controlling elevated systolic blood pressure in all adults with hypertension and recommended a similar blood-pressure goal regardless of age, with the exception of more aggressive treatment to a lower target in patients with diabetes or chronic kidney disease. ${ }^{5}$ The 2014 guidelines of the Eighth Joint National Committee recommended three important changes to the 2003 guidelines: focusing on diastolic (rather than systolic) blood pressure for adults under the age of 60 years and setting more conservative blood-pressure goals for adults 60 years of age or older $(150 / 90 \mathrm{~mm} \mathrm{Hg})$ and for patients with diabetes or chronic kidney disease $\left(140 / 90 \mathrm{~mm} \mathrm{Hg}\right.$ ) (Table 1). ${ }^{6}$ As compared with the recommendations in the previous guidelines, implementation of the 2014 guidelines would make approximately $1 \%$ of young adults and $8 \%$ of older adults ineligible to receive hypertension-lowering treatment. However, an estimated 28 million adults still would have uncontrolled hypertension according to the relaxed standards. ${ }^{4}$

Recently, the American College of Cardiology and the American Heart Association called for the inclusion of cost-effectiveness assessments and recommendations in practice guidelines. ${ }^{7}$ The main objective of this study was to estimate the incremental health gains and cost-effectiveness of implementing the strongest recommendations for hypertension therapy (i.e., those based on the results of clinical trials) in the 2014 guidelines among U.S. adults.

\section{METHODS STUDY MODEL}

The Cardiovascular Disease Policy Model is a computer-simulation, state-transition model of the incidence, prevalence, mortality, and costs of coronary heart disease and stroke among persons between the ages of 35 and 94 years in the United States. (For an overview of the model, see the Methods section and Fig. S1 in the Supplementary Appendix, available 
with the full text of this article at NEJM.org.) We estimated risk-factor exposure levels and classifications according to age and sex on the basis of survey-weighted analyses of the National Health and Nutrition Examination Survey (NHANES) ${ }^{8}$ from 2007 through 2010. The model uses competing-risk Cox proportional-hazards regression equations estimated from the results of the Framingham Heart Study to predict the incidence of coronary heart disease, stroke, and death from noncardiovascular causes among persons without cardiovascular disease, on the basis of age, sex, systolic and diastolic blood pressure, selfreported use or nonuse of antihypertensive medications, levels of high-density-lipoprotein and low-density-lipoprotein cholesterol, and status regarding chronic kidney disease, smoking, and diabetes mellitus. The model also predicts subsequent life-years and rates of cardiovascular events, coronary revascularization procedures, and death from cardiovascular causes or any cause among patients with cardiovascular disease. The model was calibrated to reproduce U.S. national data on myocardial infarction, stroke, and death from cardiovascular causes or any cause in 2010 to within less than $1 \%$ of absolute-number targets for each sex and 10-year age category.

\section{BLOOD-PRESSURE VARIABLES AND TREATMENT ASSUMPTIONS}

In NHANES from 2007 through 2010, systolic blood pressure was categorized as less than $140 \mathrm{~mm} \mathrm{Hg}, 140$ to $159 \mathrm{~mm} \mathrm{Hg}$ (stage 1 hypertension), or $160 \mathrm{~mm} \mathrm{Hg}$ or higher (stage 2 hypertension). To assess the 2014 guideline recommendations for adults between the ages of 60 and 74 years, we further divided stage 1 hypertension into 140 to $149 \mathrm{~mm} \mathrm{Hg}$ and 150 to $159 \mathrm{~mm} \mathrm{Hg}$. Categories for diastolic blood pressure were less than $90 \mathrm{~mm} \mathrm{Hg}, 90$ to $99 \mathrm{~mm}$ $\mathrm{Hg}$ (stage 1 hypertension), and $100 \mathrm{~mm} \mathrm{Hg}$ or higher (stage 2 hypertension). Patients were considered to have untreated hypertension if they answered no to the following two questions on NHANES: "Because of your high blood pressure or hypertension, have you ever been told to take prescribed medicine?" and "Are you currently taking medication to lower your blood pressure?"

In our study, we assumed that a reduction in the risk of cardiovascular disease was due to a reduction in blood pressure ${ }^{9}$ and that blood pressure was lowered to a similar extent across drug classes in comparisons of standard doses per class. ${ }^{10,11}$ Using data from the Prospective Studies Collaboration, ${ }^{12}$ a meta-analysis of 61 prospective studies of vascular risk factors and cause-specific mortality involving 1 million participants, we started by calculating observational age-specific relative risks and $95 \%$ confidence intervals for coronary heart disease and stroke according to a change of $10 \mathrm{~mm} \mathrm{Hg}$ in systolic blood pressure or $5 \mathrm{~mm} \mathrm{Hg}$ in diastolic blood pressure. ${ }^{12}$

We calibrated age-specific relative risks to be within 0.02 of these estimates and overall relative risks within the $95 \%$ confidence intervals for the summary estimates from a large meta-analysis of randomized clinical trials of hypertension treatment (see the Methods section and Tables S2 and S3 in the Supplementary Appendix). ${ }^{9}$ We validated the resulting assumptions with respect to relative risk for the treatment of systolic blood pressure in patients between the ages of 60 and 74 years by simulating the treatment and placebo groups of the Systolic Hypertension in the Elderly Program (SHEP) trial ${ }^{13}$ and comparing simulated 
relative risks with those observed in the trial (Table 2, and Table S4 in the Supplementary Appendix).

For each standard-dose or half-standard-dose medication, the reduction in blood pressure was calculated on the basis of the pretreatment blood pressure (Table S5 in the Supplementary Appendix). Variance in the change in blood pressure associated with antihypertensive treatment was based on the standard deviation for the main estimated change in blood pressure observed in a meta-analysis. ${ }^{10}$

For consistency, our main analyses assumed a medication adherence rate of $75 \%$, as observed in the same clinical trials that were used to estimate relative risks of treatment. ${ }^{9}$ The costs of hypertension treatment included medications, monitoring, and side effects (Table S6 in the Supplementary Appendix). Medication costs were calculated as the means of the lowest wholesale prices for numbers of standard doses across drug classes in the 2014 Red Book; combination pills were included when available. ${ }^{14}$ Rates of side effects of medications were based on a meta-analysis of treatment trials for common events ${ }^{10}$ and on postmarketing reports for rare events (Table S6 in the Supplementary Appendix). We translated rates of adverse events into impairments in quality-adjusted life-years (QALYs) and added costs related to events ranging from transient symptoms accompanied by an office visit (common event; QALY penalty of 0.23 per day), to adverse effects requiring hospitalization (infrequent event; QALY penalty of 0.50 per day), to death (rare event).

\section{MAIN ANALYSIS}

A status quo simulation provided a projection of events from coronary heart disease and stroke, costs, and QALYs for the U.S. adult population between the ages of 35 and 74 years during the period from 2014 through 2024, on the assumption that untreated patients would remain untreated. Simulated strategies for hypertension treatments reduced events from coronary heart disease and stroke, reduced costs, and added QALYs. We assumed that hypertension treatment would reduce rates of death from hypertensive heart disease and renal failure, but to be conservative, we assumed no change in future costs associated with these effects. In an analysis of secondary prevention, we simulated treatment to a target blood pressure of 140/90 mm Hg in patients with hypertension who were currently untreated and who had a history of stroke or coronary heart disease (approximately one fifth of patients with chronic cardiovascular disease). ${ }^{8}$ For primary prevention, we simulated three treatment groups, with each group added to treatment in patients with cardiovascular disease and untreated hypertension: patients with stage 2 hypertension, patients with stage 1 hypertension and diabetes or chronic kidney disease, and patients with stage 1 hypertension but without diabetes or chronic kidney disease. We assessed incremental cost-effectiveness ratios (which were calculated as the incremental change in costs divided by the incremental change in QALYs) as follows: costs of less than $\$ 50,000$ per QALY gained were considered to be cost-effective, costs ranging from $\$ 50,000$ to less than $\$ 150,000$ per QALY gained were considered to be of intermediate value, and costs of $\$ 150,000$ or more per QALY gained were considered to be of low value. ${ }^{7}$ All analyses were approached from a payer's perspective. All future costs and QALYs were discounted annually by 3\% of the values for the previous year, according to standard practice. 
All data analyses for this study involved secondary analyses of publicly available, deidentified data. For this reason, no ethics board approval was sought for this study.

\section{SENSITIVITY ANALYSES}

We used lower and upper uncertainty boundaries for all main variables to perform one-way sensitivity analyses (Table 2, and Table S6 in the Supplementary Appendix). In addition, we modeled adherence levels that were 50\% and $75 \%$ lower than those in clinical trials, penalties for pilltaking disutility (i.e., a decrease in the quality of life associated with taking a medication), and a 1-year lag in achieving the target blood pressure. For the effect of antihypertensive treatment on all-cause mortality, we assumed an upper boundary for the relative risk of 0.95 for younger adults for each reduction of $5 \mathrm{~mm} \mathrm{Hg}$ in diastolic blood pressure and the possibility of an increased risk among older adults (relative risk, 1.02 for each reduction of $10 \mathrm{~mm} \mathrm{Hg}$ systolic blood pressure, on the basis of the upper boundary of the estimate for all-cause mortality in the SHEP trial). ${ }^{13} \mathrm{We}$ also determined the threshold at which the treatment of patients with cardiovascular disease and those with stage 2 hypertension was no longer cost-saving (cost-neutral threshold). We used probabilistic (Monte Carlo) simulation to sample uncertainty distributions with respect to the effectiveness of blood-pressure lowering with the use of antihypertensive drugs, the relative risk reduction in cardiovascular disease with treatment, reductions in quality of life due to side effects of medications, costs related to side effects, and drug and monitoring costs. Uncertainty distributions were randomly sampled 1000 times, and 95\% uncertainty intervals were calculated.

\section{RESULTS}

\section{MAIN ANALYSES}

The Cardiovascular Disease Policy Model simulations accurately reproduced pooled results of trials of antihypertensive medications, and the SHEP trial simulation accurately reproduced the results of the actual trial (Tables S3 and S4 in the Supplementary Appendix). On average, on the basis of the 2014 guidelines, approximately 860,000 persons with existing cardiovascular disease and hypertension who are not being treated with antihypertensive medications would be eligible for treatment (secondary prevention) every year during the period from 2014 through 2024. Treatment with a target blood pressure of 140/90 $\mathrm{mm} \mathrm{Hg}$ for such patients was projected to prevent approximately 16,000 cardiovascular events (Table 3) and approximately 6000 deaths from cardiovascular causes annually.

In addition, another 8.6 million currently untreated patients between the ages of 35 and 74 years who have hypertension but no cardiovascular disease would also be eligible for treatment (primary prevention) each year. Achieving guidelines targets in these patients would prevent approximately 41,000 cardiovascular events and 7000 deaths from cardiovascular causes annually and result in cost savings, as compared with the status quo (Table 3). Achieving treatment goals for both primary and secondary prevention would prevent about 56,000 cardiovascular events and 13,000 deaths from cardiovascular causes annually. 
When treatment was sequentially assessed in progressively less cost-effective strategies, incremental cost-effectiveness ratios were found to be cost-saving for secondary prevention in all men with preexisting cardiovascular disease and for primary prevention in all men with stage 2 hypertension and in those between the ages of 45 and 74 years with stage 1 hypertension (Fig. 1, and Tables S7 through S11 and Fig. S2 in the Supplementary Appendix). Treatment was cost-effective $(<\$ 50,000$ per QALY gained) in men under the age of 45 years with stage 1 hypertension. Treatment was also cost-saving for secondary prevention in women with preexisting cardiovascular disease and in those between the ages of 45 and 74 years with stage 2 hypertension. In addition, treatment was cost-effective for primary prevention in women between the ages of 35 and 44 years with stage 2 hypertension and in those between the ages of 45 and 74 years with stage 1 hypertension. By comparison, treating women between the ages of 35 and 44 years who had stage 1 hypertension was of intermediate value for those with diabetes or chronic kidney disease $(\$ 125,000$ per QALY gained) and was of low value for those without diabetes or chronic kidney disease $(\$ 181,000$ per QALY gained).

\section{PROBABILISTIC ANALYSIS}

Almost all probabilistic sensitivity analyses (>98\% of simulation results) predicted cost savings for treatment of patients with stage 2 hypertension, except for women in the age group of 35 to 44 years (Fig. S3 in the Supplementary Appendix). More than 98\% of probabilistic simulations were cost-effective for patients with stage 1 hypertension who were 45 years of age or older, whether male or female. About $66 \%$ of simulations for men between the ages of 35 and 44 years who had stage 1 hypertension without diabetes or chronic kidney disease and $92 \%$ of simulations for women between the ages of 35 and 44 years who had stage 2 hypertension were cost-effective, but almost none were cost-saving. None of the results for women with stage 1 hypertension between the ages of 35 and 44 years were cost-effective.

\section{SENSITIVITY ANALYSES}

We projected that treatment costs could more than triple for men with cardiovascular disease ( $\$ 1,280$ more invested per patient annually) or almost double for men with stage 2 hypertension ( $\$ 600$ more) before these strategies would no longer save costs. The corresponding additional investments for women between the ages of 45 and 74 years were up to $\$ 650$ higher (for secondary prevention in patients with cardiovascular disease) or $\$ 260$ higher (for primary prevention in patients with stage 2 hypertension).

In one-way sensitivity analyses of assumptions with respect to effectiveness, adherence, costs of monitoring and medications, and side-effect frequency, all primary prevention strategies in all men and in women with stage 2 hypertension were projected to be costeffective (Table S12 in the Supplementary Appendix). Strategies for women with stage 1 hypertension between the ages of 35 and 59 years were projected to range from $\$ 51,000$ to $\$ 100,000$ per QALY gained (thus falling into the intermediatevalue range) on the assumption that the diastolic blood-pressure level would be reduced by $1.6 \mathrm{~mm} \mathrm{Hg}$ less, drug costs would be increased by a factor of 2.4, monitoring would be twice as frequent, or side effects would be twice as costly or 50\% more severe. The treatment of women between 
the ages of 35 and 44 years without diabetes or chronic kidney disease was cost-effective only if an additional $\$ 150$ or more could be saved per person treated each year. Treatment of women between the ages of 60 and 74 years with stage 1 hypertension was of intermediate value on the assumption that drug costs would increase by a factor of 2.4. Health gains from hypertension treatment persisted among all adults between the ages of 60 and 74 years and among men under the age of 60 years with stage 2 hypertension, even on the assumption that the inconvenience of taking antihypertensive medications would decrease the quality of life. The same pill-taking disutility led to a projected loss in QALYs in all patients with stage 1 hypertension and in women under the age of 60 years with stage 2 hypertension. Because lower adherence reduced effectiveness and costs in equal proportions, a reduction of $25 \%$ or $50 \%$ in the main assumption for adherence (effectively, adherence rates of 56\% and 38\%, respectively) had little effect on the results. The assumption of full intervention costs but a 1-year delay in realizing health gains attenuated incremental cost-effectiveness ratios only slightly.

\section{DISCUSSION}

Our model predicts that the achievement of goals for the treatment of hypertension as outlined in the 2014 guidelines would be cost-saving in reducing mortality and morbidity associated with cardiovascular disease in previously untreated adults with hypertension. Effectiveness and cost savings were mainly driven by very favorable results that we projected for secondary prevention in patients with cardiovascular disease and for primary prevention in patients with stage 2 hypertension. In the latter group, cost savings remained robust in sensitivity analyses of effectiveness, cost, and side effects.

These findings suggest that more frequent office visits, home blood-pressure monitoring, pharmacist interventions, or interventions to improve adherence ${ }^{15}$ may add substantial value, even if they require an additional annual investment of up to $\$ 1,230$ per patient in men with cardiovascular disease, $\$ 600$ in men with stage 2 hypertension without cardiovascular disease, and $\$ 650$ in women with cardiovascular disease. In a hypertensiontreatment protocol at Kaiser Permanente Northern California, the use of trained medical assistants and extended monitoring visits increased the proportion of patients in whom hypertension was controlled from $44 \%$ to $87 \%$ during a 10-year period. ${ }^{16}$ A 2013 Science Advisory of the American Heart Association, the American College of Cardiology, and the Centers for Disease Control and Prevention also recommended the use of hypertensiontreatment algorithms ${ }^{17}$ for multiple-provider and multipleintervention approaches.

We projected that achieving the blood-pressure treatment goal of $150 / 90 \mathrm{~mm} \mathrm{Hg}$ for patients between the ages of 60 and 74 years, as recommended in the 2014 guidelines, would be cost-effective, even when we assumed a higher rate of medication side effects in this group. However, patients between the ages of 60 and 74 years have variable levels of functional status and susceptibility to side effects of medications and adverse events. Better predictors of adverse effects of medications are needed to guide the decision to withhold or withdraw treatment from individual patients in this age group. Controversy persists about the systolic blood-pressure treatment target of $150 \mathrm{~mm} \mathrm{Hg}$ in the 2014 guidelines, ${ }^{18}$ and future research must address the question of whether a lower target is indicated and, if so, in which patients. 
For short-term treatment of stage 1 hypertension in patients between the ages of 35 and 44 years, our simulations projected cost-effectiveness in men and intermediate or low value in women. However, longitudinal cohort studies with long-term follow-up suggest that a history of high blood pressure dating back to young adulthood is an independent predictor of risk for cardiovascular events in later life, ${ }^{19-23}$ an effect that was not modeled in this study.

Although our analysis focused on the 2014 guidelines, our projections of health benefits and cost-effectiveness are broadly consistent with the results of previous cost-effectiveness analyses of hypertension treatment. ${ }^{3,24,25}$ The methods and reporting of this study conform to Consolidated Health Economic Evaluation Reporting Standards (CHEERS) ${ }^{26}$ and Quality of Health Economic Studies instrument standards recommended for cost-effectiveness analyses of U.S. guidelines regarding risk factors for cardiovascular disease. ${ }^{7,27}$ Effectiveness assumptions were grounded in a large meta-analysis of randomized trials of antihypertensive treatments, and the simulation of the SHEP trial produced results similar to those observed in the actual trial.

However, like all other computer-simulation analyses, ours was limited by reliance on multiple assumptions and data derived from multiple sources and study types. Because of limited evidence from clinical trials and the need to consider the complications of frailty, cognitive function, and an increased risk of side effects among patients 75 years of age or older, we limited our analyses to persons between the ages of 35 and 74 years. Because of our conservative approach, we did not capture disability or costs attributable to hypertensive heart disease, peripheral arterial disease, or end-stage renal disease and other noncardiovascular outcomes associated with hypertension. Therefore, we probably underestimated cost savings and QALY gains associated with hypertension treatment. We did not analyze effective diet and lifestyle interventions for lowering blood pressure in patients with hypertension, ${ }^{28,29}$ and we did not analyze the cost-effectiveness or other relative merits of specific antihypertensive medication classes or combinations. ${ }^{30-32}$ Finally, we did not analyze the potential synergistic benefits of simultaneous implementation of the 2014 hypertension guidelines and guidelines for controlling high cholesterol, diabetes, obesity, and other risk factors for cardiovascular disease, nor did we assess the value of hypertension treatment as part of an integrated guideline for managing all risk factors for cardiovascular disease on the basis of calculated global risk. ${ }^{24,25,33}$

In conclusion, our model results suggest that controlling hypertension in untreated patients according to the 2014 guidelines not only would prevent about 56,000 cardiovascular events and 13,000 deaths from cardiovascular causes annually but also would result in cost savings. Among the groups that we considered, the treatment of men and women with cardiovascular disease and those with stage 2 hypertension without cardiovascular disease appeared to provide the most value, and the treatment of women under the age of 60 years with stage 1 hypertension appeared to provide the least value.

\section{Supplementary Material}

Refer to Web version on PubMed Central for supplementary material. 


\section{Acknowledgments}

Supported by a grant from the National Heart, Lung, and Blood Institute (R01 HL107475-01), a grant from the American Heart Association Founder's Affiliate Clinical Research Program (10CRP4140089), and a Columbia University Irving scholarship (all to Dr. Moran); and by a grant from the National Institute for Neurological Disorders and Stroke (U54NS081760, to Dr. Bibbins-Domingo).

We thank Dr. David Fairley for designing and programming the Monte Carlo function of the Cardiovascular Disease Policy Model software.

\section{References}

1. US Burden of Disease Collaborators. The state of US health, 1990-2010: burden of diseases, injuries, and risk factors. JAMA. 2013; 310:591-608. [PubMed: 23842577]

2. Danaei G, Ding EL, Mozaffarian D, et al. The preventable causes of death in the United States: comparative risk assessment of dietary, lifestyle, and metabolic risk factors. PLoS Med. 2009; 6(4):e1000058. [PubMed: 19399161]

3. Cutler DM, Long G, Berndt ER, et al. The value of antihypertensive drugs: a perspective on medical innovation. Health Aff (Millwood). 2007; 26:97-110. [PubMed: 17211019]

4. Navar-Boggan AM, Pencina MJ, Williams K, Sniderman AD, Peterson ED. Proportion of US adults potentially affected by the 2014 hypertension guideline. JAMA. 2014; 311:1424-9. [PubMed: 24682242]

5. Chobanian AV, Bakris GL, Black HR, et al. The Seventh Report of the Joint National Committee on Prevention, Detection, Evaluation, and Treatment of High Blood Pressure: the JNC 7 report. JAMA. 2003; 289:2560-72. [PubMed: 12748199]

6. James PA, Oparil S, Carter BL, et al. 2014 Evidence-based guideline for the management of high blood pressure in adults: report from the panel members appointed to the Eighth Joint National Committee (JNC 8). JAMA. 2014; 311:507-20. [PubMed: 24352797]

7. Anderson JL, Heidenreich PA, Barnett PG, et al. ACC/AHA statement on cost/ value methodology in clinical practice guidelines and performance measures: a report of the American College of Cardiology/American Heart Association Task Force on Performance Measures and Task Force on Practice Guidelines. Circulation. 2014; 129:2329-45. [PubMed: 24677315]

8. National Health and Nutrition Survey home page. http://www.cdc.gov/nchs/about/major/nhanes/ datalink.htmhttp://www.cdc.gov/nchs/about/major/nhanes/datalink.htm

9. Law MR, Morris JK, Wald NJ. Use of blood pressure lowering drugs in the prevention of cardiovascular disease: meta-analysis of 147 randomised trials in the context of expectations from prospective epidemiological studies. BMJ. 2009; 338:b1665. [PubMed: 19454737]

10. Law MR, Wald NJ, Morris JK, Jordan RE. Value of low dose combination treatment with blood pressure lowering drugs: analysis of 354 randomised trials. BMJ. 2003; 326:1427. [PubMed: 12829555]

11. Turnbull F. Effects of different blood-pressure-lowering regimens on major cardiovascular events: results of prospectively-designed overviews of randomised trials. Lancet. 2003; 362:1527-35. [PubMed: 14615107]

12. Lewington S, Clarke R, Qizilbash N, Peto R, Collins R. Age-specific relevance of usual blood pressure to vascular mortality: a meta-analysis of individual data for one million adults in 61 prospective studies. Lancet. 2002; 360:1903-13. [PubMed: 12493255]

13. SHEP Cooperative Research Group. Prevention of stroke by antihypertensive drug treatment in older persons with iso-lated systolic hypertension: final results of the Systolic Hypertension in the Elderly Program (SHEP). JAMA. 1991; 265:3255-64. [PubMed: 2046107]

14. Average wholesale price (AWP) policy. Red Book Drug References. 2014. http://redbook.com/ redbook/awphttp://redbook.com/redbook/awp

15. Glynn LG, Murphy AW, Smith SM, Schroeder K, Fahey T. Interventions used to improve control of blood pressure in patients with hypertension. Cochrane Database Syst Rev. 2010; 3:CD005182. [PubMed: 20238338] 
16. Jaffe MG, Lee GA, Young JD, Sidney S, Go AS. Improved blood pressure control associated with a large-scale hypertension program. JAMA. 2013; 310:699-705. [PubMed: 23989679]

17. Go AS, Bauman MA, Coleman King SM, et al. An effective approach to high blood pressure control: a science advisory from the American Heart Association, the American College of Cardiology, and the Centers for Disease Control and Prevention. Hypertension. 2014; 63:878-85. [PubMed: 24243703]

18. Wright JT Jr, Fine LJ, Lackland DT, Ogedegbe G, Dennison Himmelfarb CR. Evidence supporting a systolic blood pressure goal of less than $150 \mathrm{~mm} \mathrm{Hg}$ in patients aged 60 years or older: the minority view. Ann Intern Med. 2014; 160:499-503. [PubMed: 24424788]

19. Harris T, Cook EF, Kannel WB, Goldman L. Proportional hazards analysis of risk factors for coronary heart disease in individuals aged 65 or older: the Framingham Heart Study. J Am Geriatr Soc. 1988; 36:1023-8. [PubMed: 2971709]

20. Gray L, Lee IM, Sesso HD, Batty GD. Blood pressure in early adulthood, hypertension in middle age, and future cardiovascular disease mortality: HAHS (Harvard Alumni Health Study). J Am Coll Cardiol. 2011; 58:2396-403. [PubMed: 22115646]

21. McCarron P, Smith GD, Okasha M, McEwen J. Blood pressure in young adult-hood and mortality from cardiovascular disease. Lancet. 2000; 355:1430-1. [PubMed: 10791531]

22. Miura K, Daviglus ML, Dyer AR, et al. Relationship of blood pressure to 25-year mortality due to coronary heart disease, cardiovascular diseases, and all causes in young adult men: the Chicago Heart Association Detection Project in Industry. Arch Intern Med. 2001; 161:1501-8. [PubMed: 11427097]

23. McCarron P, Okasha M, McEwen J, Davey Smith G. Blood pressure in early life and cardiovascular disease mortality. Arch Intern Med. 2002; 162:610-1. [PubMed: 11871936]

24. Eddy DM, Adler J, Patterson B, Lucas D, Smith KA, Morris M. Individualized guidelines: the potential for increasing quality and reducing costs. Ann Intern Med. 2011; 154:627-34. [PubMed: 21536939]

25. Sussman J, Vijan S, Hayward R. Using benefit-based tailored treatment to improve the use of antihypertensive medications. Circulation. 2013; 128:2309-17. [PubMed: 24190955]

26. Husereau D, Drummond M, Petrou S, et al. Consolidated Health Economic Evaluation Reporting Standards (CHEERS) statement. BMJ. 2013; 346:f1049. abstract. [PubMed: 23529982]

27. Ofman JJ, Sullivan SD, Neumann PJ, et al. Examining the value and quality of health economic analyses: implications of utilizing the QHES. J Manag Care Pharm. 2003; 9:53-61. [PubMed: 14613362]

28. Appel LJ, Champagne CM, Harsha DW, et al. Effects of comprehensive lifestyle modification on blood pressure control: main results of the PREMIER clinical trial. JAMA. 2003; 289:2083-93. [PubMed: 12709466]

29. Appel LJ, Moore TJ, Obarzanek E, et al. A clinical trial of the effects of dietary patterns on blood pressure. N Engl J Med. 1997; 336:1117-24. [PubMed: 9099655]

30. Heidenreich PA, Davis BR, Cutler JA, et al. Cost-effectiveness of chlorthalidone, amlodipine, and lisinopril as first-step treatment for patients with hypertension: an analysis of the Antihypertensive and Lipid-Lowering Treatment to Prevent Heart Attack Trial (ALLHAT). J Gen Intern Med. 2008; 23:509-16. [PubMed: 18228109]

31. Timbie JW, Hayward RA, Vijan S. Diminishing efficacy of combination therapy, responseheterogeneity, and treatment intolerance limit the attainability of tight risk factor control in patients with diabetes. Health Serv Res. 2010; 45:437-56. [PubMed: 20070387]

32. Ramsey SD, Neil N, Sullivan SD, Perfetto E. An economic evaluation of the JNC hypertension guidelines using data from a randomized controlled trial. J Am Board Fam Pract. 1999; 12:10514. [PubMed: 10220232]

33. Sundström J, Arima H, Woodward M, et al. Blood pressure-lowering treatment based on cardiovascular risk: a meta-analysis of individual patient data. Lancet. 2014; 384:591-8. [PubMed: 25131978] 


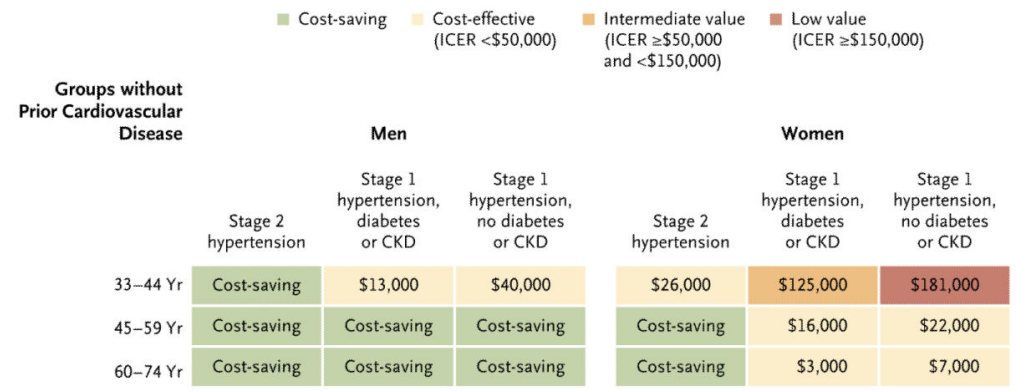

Figure 1.

Projected Average Cost-Effectiveness of Full Implementation of the 2014 Guidelines for Hypertension Treatment in Patients without Cardiovascular Disease, According to Sex, Age, Hypertension Stage, and Status with Respect to Diabetes and Chronic Kidney Disease. Treatment of each group is compared with the strategy outlined in the previous incremental step in the study model for patients in the same age category. Patients with stage 2 hypertension who do not have cardiovascular disease are compared with patients with cardiovascular disease. CKD denotes chronic kidney disease, and ICER incremental costeffectiveness ratio. 


\section{Table 1}

Recommendations for Hypertension Treatment in the 2014 Guidelines for Adults, According to Major Treatment Group.

\begin{tabular}{lcc}
\hline Treatment Group & $\begin{array}{c}\text { Age Range } \\
\text { in Study }\end{array}$ & $\begin{array}{c}\text { Blood-Pressure Treatment } \\
\text { Goal for Main Analysis }\end{array}$ \\
\hline $\begin{array}{c}\text { Age }<60 \text { yr, without diabetes } \\
\text { or chronic kidney disease }\end{array}$ & $35-59 \mathrm{yr}$ & Diastolic $<90 \mathrm{~mm} \mathrm{Hg}$ \\
$\begin{array}{c}\text { Age } 260 \mathrm{yr} \text {, without diabetes } \\
\text { or chronic kidney disease }\end{array}$ & $60-74 \mathrm{yr}$ & $\begin{array}{c}\text { Systolic }<150 \mathrm{~mm} \mathrm{Hg} \text { and } \\
\text { diastolic }<90 \mathrm{~mm} \mathrm{Hg}\end{array}$ \\
$\begin{array}{c}\text { All adults, with diabetes or } \\
\text { chronic kidney disease }\end{array}$ & $35-74 \mathrm{yr}$ & $\begin{array}{c}\text { Systolic }<140 \mathrm{~mm} \mathrm{Hg} \text { and } \\
\text { diastolic }<90 \mathrm{~mm} \mathrm{Hg}\end{array}$ \\
\hline
\end{tabular}


Table 2

Main Effectiveness Assumptions and Uncertainty Ranges Used for Estimating the Cost-Effectiveness of Implementation of the 2014 Guidelines for Hypertension Treatment.*

\begin{tabular}{|c|c|c|c|}
\hline Variable & Main Estimate & Lower Estimate & Upper Estimate \\
\hline \multicolumn{4}{|l|}{$\begin{array}{l}\text { Average relative risk per } 10 \mathrm{~mm} \mathrm{Hg} \text { reduction in systolic blood pressure } \\
\text { or } 5 \mathrm{~mm} \mathrm{Hg} \text { reduction in diastolic blood pressure (range) })^{\dagger}\end{array}$} \\
\hline \multicolumn{4}{|l|}{ Age $35-59$ yr } \\
\hline Coronary heart disease & $0.73(0.72-0.74)$ & $0.70(0.67-0.72)$ & $0.77(0.76-0.78)$ \\
\hline Stroke & $0.64(0.61-0.66)$ & $0.59(0.54-0.63)$ & $0.69(0.68-0.69)$ \\
\hline Death from any cause & $0.86(0.83-0.89)$ & 0.76 & 0.95 \\
\hline \multicolumn{4}{|l|}{ Age $60-74$ yr } \\
\hline Coronary heart disease & $0.77(0.74-0.78)$ & $0.74(0.72-0.76)$ & $0.79(0.76-0.81)$ \\
\hline Stroke & $0.69(0.66-0.71)$ & $0.64(0.62-0.64)$ & $0.74(0.69-0.78)$ \\
\hline Death from any cause & $0.91(0.91-0.92)$ & 0.80 & 1.02 \\
\hline \multicolumn{4}{|l|}{ Average systolic blood-pressure reduction $-\mathrm{mm} \mathrm{Hg}^{\ddagger}$} \\
\hline \multicolumn{4}{|l|}{ Stage 2 hypertension } \\
\hline $\begin{array}{l}\text { Age }<60 \mathrm{yr} \text {; pretreatment, } \geq 160 \mathrm{~mm} \mathrm{Hg} \text {; target, } 140 \mathrm{~mm} \mathrm{Hg} \text {; } \\
\text { 3.0-4.0 standard-dose medications }\end{array}$ & $31.0-34.7$ & $26.0-29.4$ & $36.0-39.9$ \\
\hline 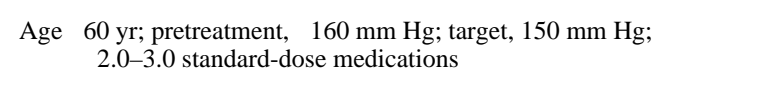 & $22.1-24.2$ & $18.1-18.9$ & $27.2-29.2$ \\
\hline \multicolumn{4}{|l|}{ Stage 1 hypertension } \\
\hline $\begin{array}{l}\text { Age }<60 \mathrm{yr} \text {; pretreatment, } 140-159 \mathrm{~mm} \mathrm{Hg} \text {; target, }<140 \mathrm{~mm} \mathrm{Hg} \text {; } \\
0.5-2.0 \text { standard-dose medications }\end{array}$ & $7.9-10.9$ & $5.9-8.3$ & $9.9-13.4$ \\
\hline $\begin{array}{l}\text { Age } \ 60 \mathrm{yr} ; \text { pretreatment, } 150-159 \mathrm{~mm} \mathrm{Hg} \text {; target, }<150 \mathrm{~mm} \mathrm{Hg} \text {; } \\
0.5 \text { standard-dose medication }\end{array}$ & 7.1 & 3.2 & 11.0 \\
\hline \multicolumn{4}{|l|}{ Average diastolic blood-pressure reduction $-\mathrm{mm} \mathrm{Hg}$} \\
\hline $\begin{array}{l}\text { Stage } 2 \text { hypertension; all ages; target, } 90 \mathrm{~mm} \mathrm{Hg} ; 3.0 \text { standard-dose } \\
\text { medications }\end{array}$ & 17.1 & 12.0 & 22.2 \\
\hline $\begin{array}{l}\text { Stage } 1 \text { hypertension; all ages; target, } 90 \mathrm{~mm} \mathrm{Hg} ; 1.0 \text { standard-dose } \\
\text { medication }\end{array}$ & 5.3 & 3.7 & 6.9 \\
\hline \multicolumn{4}{|c|}{$\begin{array}{l}{ }^{\dagger} \text { Data in parentheses are the lowest and highest relative risks according to age and sex among main estimates and among estimates of upper and } \\
\text { lower } 95 \% \text { confidence intervals. The ranges for relative risks of death from any cause are not included for the lower and upper estimates because } \\
\text { no variability according to age or sex was assumed on the basis of available evidence. }\end{array}$} \\
\hline
\end{tabular}

N Engl J Med. Author manuscript; available in PMC 2015 July 29. 


\section{Table 3}

Projected Average Annual Incremental Results of Providing Therapy for Patients with Untreated Hypertension between the Ages of 35 and 74 Years (2014-2024).*

\begin{tabular}{|c|c|c|c|c|c|}
\hline Strategy & $\begin{array}{c}\text { Newly Treated } \\
\text { Patients, } \\
\text { as Compared } \\
\text { with Status } \\
\text { Quo }\end{array}$ & $\begin{array}{l}\text { Cardiovascular } \\
\text { Events Averted, } \\
\text { as Compared } \\
\text { with Status Quo }\end{array}$ & $\begin{array}{l}\text { Change in } \\
\text { Cardiovascular } \\
\text { Costs, } \\
\text { as Compared } \\
\text { with Status Quo } \\
\text { millions of } \$\end{array}$ & $\begin{array}{l}\text { ICER, } \\
\text { as Compared } \\
\text { with Status } \\
\text { Quo }\end{array}$ & $\begin{array}{c}\text { ICER, } \\
\text { as Compared } \\
\text { with Previous } \\
\text { Strategy }^{\dagger}\end{array}$ \\
\hline \multicolumn{6}{|l|}{ Women } \\
\hline $\begin{array}{l}\text { Treat all patients with cardiovascular } \\
\text { disease }{ }^{t}\end{array}$ & 161,000 & 6,000 & -287 & Cost-saving & Cost-saving \\
\hline $\begin{array}{l}\text { Treat patients with stage } 2 \text { hypertension who } \\
\text { do not have cardiovascular disease }\end{array}$ & 844,000 & 15,000 & -552 & Cost-saving & Cost-saving \\
\hline $\begin{array}{l}\text { Treat patients with stage } 1 \text { hypertension plus } \\
\text { diabetes or chronic kidney disease }\end{array}$ & $1,164,000$ & 8,000 & -246 & Cost-saving & Cost-effective $\mathrm{e}^{\S}$ \\
\hline $\begin{array}{l}\text { Treat patients with stage } 1 \text { hypertension who } \\
\text { do not have diabetes or chronic kidney } \\
\text { disease }\end{array}$ & $2,487,000$ & 8,000 & -149 & Cost-saving & Cost-effective $\S^{\S}$ \\
\hline \multicolumn{6}{|l|}{ Men } \\
\hline $\begin{array}{l}\text { Treat all patients with cardiovascular } \\
\text { disease }\end{array}$ & 705,000 & 9,000 & -755 & Cost-saving & Cost-saving \\
\hline $\begin{array}{l}\text { Treat patients with stage } 2 \text { hypertension who } \\
\text { do not have cardiovascular disease }\end{array}$ & $1,948,000$ & 26,000 & $-1,640$ & Cost-saving & Cost-saving \\
\hline $\begin{array}{l}\text { Treat patients with stage } 1 \text { hypertension plus } \\
\text { diabetes or chronic kidney disease }\end{array}$ & $1,649,000$ & 20,000 & -904 & Cost-saving & Cost-saving \\
\hline $\begin{array}{l}\text { Treat patients with stage } 1 \text { hypertension who } \\
\text { do not have diabetes or chronic kidney } \\
\text { disease }\end{array}$ & $3,093,000$ & 14,000 & -122 & Cost-saving & Cost-saving \\
\hline \multicolumn{6}{|c|}{$\begin{array}{l}\text { * Data were calculated with the use of the Cardiovascular Disease Policy Model on the basis of a simulation of the } 2014 \text { guidelines of the Eighth } \\
\text { Joint National Committee for hypertension treatment. A status quo simulation provided a projection of coronary heart disease and stroke events, } \\
\text { costs, and quality-adjusted life-years (QALYs) for the U.S. adult population between the ages of } 35 \text { and } 74 \text { years during the period from } 2014 \\
\text { through 2024, on the assumption that untreated patients would remain untreated. ICER denotes incremental cost-effectiveness ratio. }\end{array}$} \\
\hline \multicolumn{6}{|c|}{$\begin{array}{l}\text { In this comparison, each incremental strategy is compared with the step before it in the study model as follows: step } 1 \text {, simulate status quo of no } \\
\text { treatment in these patients; step 2, treat all patients with untreated hypertension and cardiovascular disease and compare with step } 1 \text {; step } 3 \text {, treat } \\
\text { patients with stage } 2 \text { hypertension who do not have cardiovascular disease and compare with step } 2 \text {; step } 4 \text {, treat patients with stage } 1 \text { hypertension } \\
\text { plus diabetes or chronic kidney disease and compare with steps } 2 \text { and } 3 \text { combined; and step } 5 \text {, treat patients with stage } 1 \text { hypertension who do not } \\
\text { have diabetes or chronic kidney disease and compare with steps } 2,3 \text {, and } 4 \text { combined. }\end{array}$} \\
\hline \multicolumn{6}{|c|}{ Fatients in this group were included in analyses of all the other listed strategies, except for the status quo of no treatment. } \\
\hline
\end{tabular}

N Engl J Med. Author manuscript; available in PMC 2015 July 29. 